\title{
Increase in energetic and exploitation stability of solar systems with array of flat collectors
}

\author{
Ilya Kurasov ${ }^{1, *}$, Tatiana Shchukina ${ }^{1}$, Mariya Zherlykina $^{1}$, and Igor Potekhin ${ }^{1}$ \\ ${ }^{1}$ Voronezh State Technical University, 84, 20 let Oktjabrja street, 394006, Voronezh, Russia
}

\begin{abstract}
With the account of modern requirements of energy saving each year increase actuality of technologies of use solar energy to decrease energy consumption. Multifunctional utilization of solar radiation make able much more degree in autonomy the energy supply of buildings, that main condition in case of too far location of traditional resources and appear of faults during their supply. Because of it is considered possibility of receiving heat and electrical energy in one technical device, with high efficiency. It is offered structural solution of multifunctional flat solar collector, which rise efficiency of radiation utilization. It is analyzed degree. It is analyzed the degree of absorption of solar radiation by additional location the photo converters in the device. It is estimated the influence of occupied by semi-conductors square on total absorption coefficient. It is proved, that by occupied square with photo elements less than $20 \%$ square of collector, the decrease of heat process parameters will be in limits of 5\%. However by this it will be act neither heat, not electrical energy, which could be forwarded to systems of building life-support systems. Beside of it, for increase efficiency of solar collector it is offered additional processing of absorber's surface, which is rise degree of radiation absorption. Technology of laser weld allows to create on surface ultra-thin cell ribbing, which in forthcoming could be consider as decrease reflection roughness. Execution by this way ribbing increase panel's square and its absorption ability. By this size of cells could be from 0,5 to $4 \mathrm{~mm}$ and choose in depend of area irradiance, where will be located solar unit.
\end{abstract}

\section{Introduction}

In conditions of rise of prices on natural resources, the more and more competition capability receive renewable energy source. It is especially shows by solution the problem of energy supply of buildings, which don't have access to central nets of heat-, gas- and electricity supply [1].

More widespread and multifunctional utilized renewable source is solar energy. In result of efficient transformation of radiation it is possible to supply low-story building with heat and electrical energy and organize alternative cold-supply. As show actinometric data, source provision rate of regions, located southern $60{ }^{\circ}$ north longitude, is allow to successful utilize solar radiation in heat and transit year periods and particular compensate necessity in heating season and total supply, using additional heat-pump equipment.

\footnotetext{
*Corresponding author: ilya.kurasov@yandex.ru
} 
However rise of potential of extraction useful energy, first of all, is connected with achieve of high values in devices of catching and transforming of radiation. Search of innovation solutions in this direction will expand period of season exploitation of solar units and decrease payback period [2].

\section{Materials and methods}

Comparative estimation of two most available approaches of energy receive by using photo transformers and solar collectors show advantage of generation of heat processes. It is connected not only with high efficiency of infrared radiation utilization, but with enough significant time term of failure-free exploitation of these systems.

Spite to active innovation developments, apply to receive electro energy, semiconductors because of technological limitations have efficiency not more $25 \%$ [3]. However third generation of photovoltaic transformers significantly overtake previous, because of by developers is declared possible increase efficiency up to $45 \%$. But in manufacturing of solar batteries of this class are used rare-earth elements, which have strong toxic features, which make strong difficult their utilization after end-of-life. This leads to increase of cost of solar elements, what significantly restrict their usage for light transformation.

It needs to notify, that during the exploitation's process there is decrease of efficiency average on $1 \%$ per year because of degradation of photo-electric transformers [4], called by heating and spoiling of absorption surface. For example, increase of temperature of the silicon semi-conductors on $1{ }^{\circ} \mathrm{C}$ decrease efficiency of electrical energy production on $0,4 \ldots 0,5 \%$ [4], which significantly down its production in hours of intensive solar radiation. To repair all mentioned defects is possible with designing solar units, with which are extraction electrical and heat energy. The second from mentioned above processes executes function of semi-conductors cooling. The strict quantity of located phototransformers significantly not decrease efficiency of flat heat collectors. By this it need to notify, that selective absorption by semi-conductors ultra-violet light waves with length 0,10 to 0,38 micrometers don't complicate utilization of infrared radiation $(0,76$ to 1 micrometer). Thus it is advisable to develop and use hybrid units in innovation designing of elements for catching and transforming radiation [5..11]. The massive of multifunctional collectors compensate two kinds of loadings of buildings and increase reliability of solar systems.

For the efficient utilization of solar radiation and for the aim of receiving electricity and heat energy was developed heat collector (figure 1, 2) [12], which contains phototransformers. After passing the radiation through the transparent board and penetration into the space above the absorption panel, ultra-violet light waves, go to semi-conductors call the increasing of electron's energy and thereafter electro energy generation. By this infrared waves warm-up photo-transformers, but their location on polymer tubes with coolant make possible to dump extra heat and therefore to support enough temperature mode, which don't decrease efficiency of the electro energy generation even in hours of highest intense of solar radiation. Additional electrical energy generation supply autonomous work of solar units, which provide their long years failure-free exploitation. 


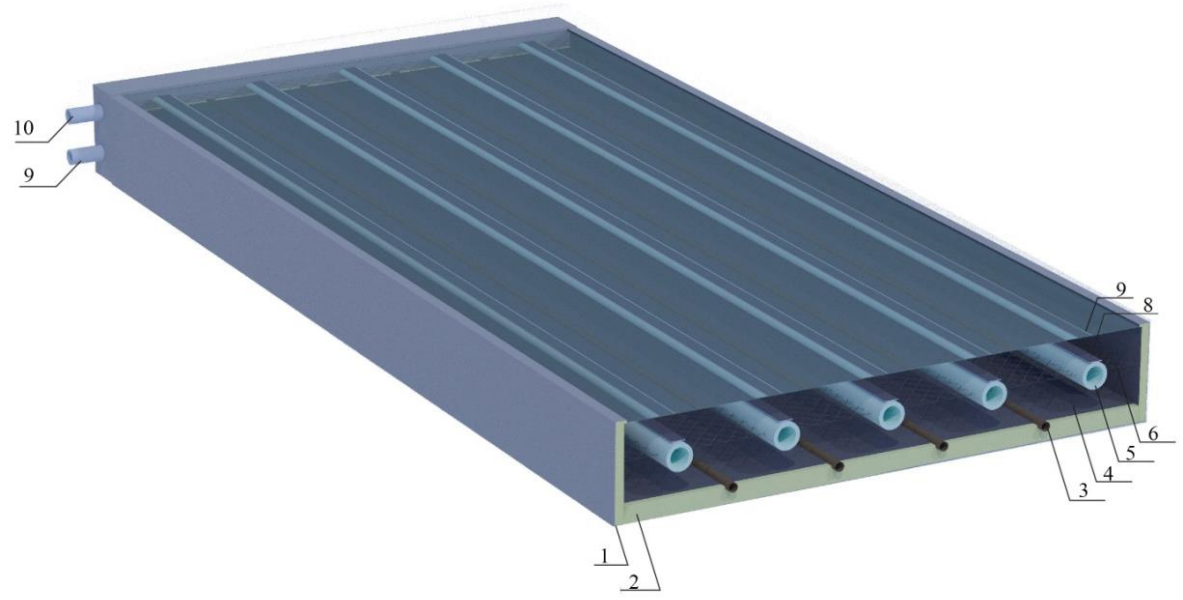

Fig. 1. Whole view of multifunctional flat solar collector: 1 - casing; 2 - heat insulation; 3 - metal tubes; 4 - absorption board; 5 -polymer tubes; 6 -thin metal grid; 8 - photo transformers; 9 transparent board; 10,11-inlet and outlet manifolds.

Assembly of polymer tubes by brazing on metal grid in consequence lead to use "hot house" effect, which appears under transparent board and lead to parameters' increase of utilization process. Warmed-up by "hothouse" effect metal grid gives heat to coolant in polymer tubes. After preliminary warm-up in polymer tubes the coolant goes to the absorption panel's tubes, which can be manufactured by traditional method, used in flat collectors.

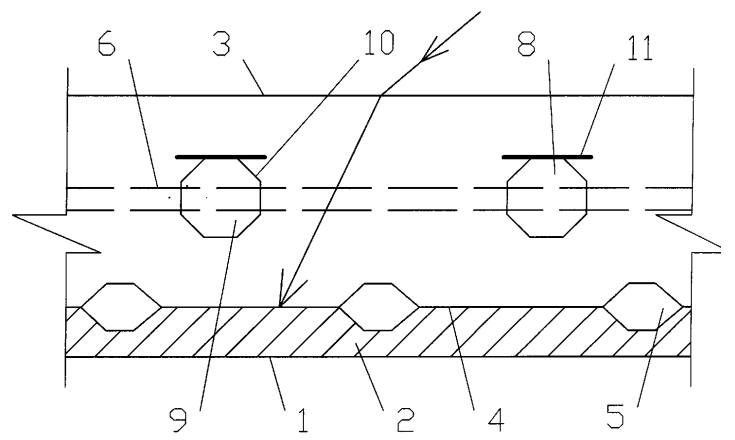

Fig. 2. Part of the across cutaway of the multifunctional flat collector's modification (signatures to the cutaway): 1 - casing; 2 - heat insulation; 3 -transparent board; 4 -absorption board; 5 - metal pipes; 6 - two layers of thin metal grid with tiny mesh; 8 - polymer pipes; 9,10 - top and bottom segments of brazed polymer tubes; 11 - photo transformers.

Despite on achieved high values of catching solar radiation by absorbers with use of well-known technologies of their surface, resources of more complete absorption of radiation still not depleted. Thus, in further, include with nanotechnologies, absorption panels will be modernized alongside with use of traditional methods of their fabrication. In this case technical development of solar heat collectors will be made by three directions: creation pored panel structure, formation micro channels and making ultra-thin roughness in absorption surface.

First two methods of increase efficiency of units make intensification of heat transfer to circulated coolant. Third method is directed to increase absorption coefficient. This 
surface's processing contributes to higher rate of catching and transforming input solar radiation, than from existed standard analogues. Beside of systematic roughness, which is ultra-thin right geometric forms on absorption surface, panel could be fabricated with micro-channels for the coolant circulation. The amount of this design solutions will increase rate of solar energy absorption and its transmit to coolant.

The offered technology of surface's processing, relate to third method of efficiency increase, consists in deposition ultra-thin ribs by laser welding. Formed by this method roughness will influence on degree of absorption of solar radiation, and increase useful absorber's square. Made according fig. 3 laser processing will create cell structure, which decrease as reflection and itself radiation of panel. By this, created ultra-thin ribs could have height from 0,1 to $3 \mathrm{~mm}$ and interval from 1 to $5 \mathrm{~mm}$. Specified sizes is regulated in dependence of resource of solar radiation for geographical location, where will be mount solar system. As northern latitude of geographical place of mount, than higher height and longer interval of ribs.

It need to notify, that after laser processing, square of absorption collector's panel can increase average on $10-50 \%$ from start mean. Because for unit size $2,01 \mathrm{~m}^{2}$ finish mean of absorber's square can be from 2,31 to $3,02 \mathrm{~m}^{2}$. Increase square from use ultra-thin ribbing allows to rise heat removal from appeared under transparent board "hothouse" effect.
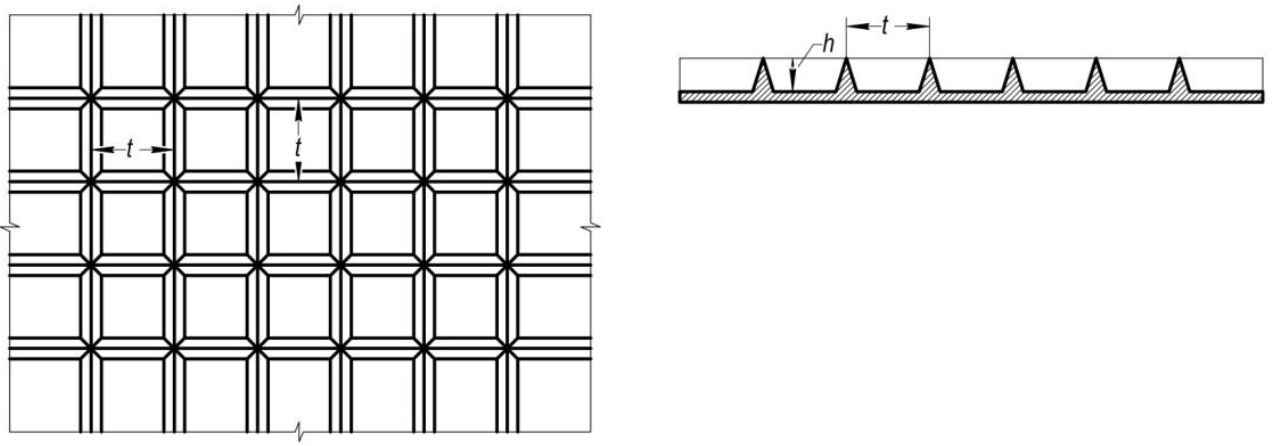

Fig. 3. Cell ribbing of absorption panel of solar collector: $h$-ribs' height, $\mathrm{mm} ; t-$ rib's interval, $\mathrm{mm}$.

Offered structural design solutions in the design of elements of solar unit will increase efficiency and combination of their use in modernized collectors will lead to higher and multifunctional level of solar energy utilization in this class of units.

\section{Results}

By absorption of solar radiation by absorber part of flat collector, the specific utilized flow is estimated by formulae [13]:

$$
E_{A}=A_{A} c_{0}\left(\frac{T}{100}\right)^{4}
$$

where $E_{A}$ - specific flow, of absorbed energy by absorber part,, $\mathrm{W} / \mathrm{m}^{2} ; A_{A}$ - coefficient of absorption of absorber's plates; $c_{0}-$ coefficient of radiation of total black matter, $\mathrm{W} /\left(\mathrm{m}^{2}\left({ }^{\circ} \mathrm{K}\right)^{4}\right)$.

In case of location in the flat collector the photo transformers, the heat flow of utilized solar energy could be find from relation: 


$$
E_{U}=A_{F} F_{F} c_{0}\left(\frac{T_{\Phi}}{100}\right)^{4}+A_{A}\left(F_{A}-F_{F}\right) c_{0}\left(\frac{T_{A}}{100}\right)^{4},
$$

where $E_{U}$ - heat flow of absorbed solar energy, W; $A_{F}$ - coefficient of absorption of semiconductors; $T_{F}, T_{A}$ - temperature of photo transformers and absorber, ${ }^{\circ} \mathrm{K} ; F_{F}, F_{A}$ - square of semi-conductors and absorption panel, $\mathrm{m}^{2}$.

By admission, that in result of "hothouse" effect temperature of considered elements will be approximately equal, it could to calculate whole coefficient of absorption:

$$
A_{0}=A_{A}+\frac{F_{F}}{F_{A}}\left(A_{F}-A_{A}\right),
$$

and then equation (2) will appear:

$$
E_{U}=A_{0} F_{A} c_{0}\left(\frac{T}{100}\right)^{4},
$$

Beside the change of absorption coefficient, it could be execute the analysis of achieved of efficiency, include for hybrid units. Values of efficiency of solar energy in dependence from structural design of units could be calculated according to recommend formulae [3, 16]

$$
\eta_{t}=\eta_{0}-k_{1} \frac{\Delta T}{I_{K}}-k_{2} \frac{\Delta T^{2}}{I_{K}},
$$

where $\eta_{t}, \eta_{0}$ - unit's efficiency, are temperature-gradient and effective optical; $\Delta T-$ drop between average temperature of coolant in collector and temperature of environment $\Delta T=0,5\left(T_{H i}+T_{H e}\right)-T_{a i},{ }^{\circ} \mathrm{C} ; T_{H i}, T_{H e}$ - temperature on input and output of collector, ${ }^{\circ} \mathrm{C} ; k_{1}, k_{2}$ - coefficients of heat loss to environment; $I_{K}$ - density of flow of solar radiation, goes to collector's glass, $\mathrm{W} / \mathrm{m}^{2}$.

For the calculation of efficiency by formulae (5) specified above examples are accepted as equal $[3,16]$ :

- for flat collectors $\eta_{0}=0,779, k_{1}=3,56, k_{2}=0,0146$;

- for vacuum collectors $\eta_{0}=0,7, k_{1}=1,33, k_{2}=0,0071$.

As it noticeable from mentioned meanings of parameters, recommended for calculations on approximated dependence (5), optical efficiency and loss to environment of flat collectors are higher, than by vacuum collectors. However in warm and transit year periods, the main factor of influence on efficiency of catching and transforming of solar energy is absorption coefficient, which are taking into account by optical efficiency. Moreover, create conditions to use more wide span wave lengths it is able to achieve higher technological level of consumption from renewable source. Thus in this case, multifunctional hybrid units, based on flat collectors are able to supply deep extraction of useful energy.

Since collector's efficiency main part depends from radiation absorption efficiency, we consider probable consequences from location photo-transformers in the unit casing. We assume, that absorber's surface is painted to black and absorption coefficient is 0,95 and for semi-conductors with smooth surface $-0,7$. Thus total absorption coefficient, calculated 
by dependence (3) for $1 \mathrm{~m}^{2}$ of absorber, shows (fig. 4), that by location of semi-conductors with square not less $20 \%$ of collector's square, its decrease will be in boundary of $5 \%$.

However in this case the unit will produce not only heat, but electrical energy, so will be acting utilization of more wide span of waves length. Beside of it, by laser processing of unit's surface, the increase of absorbers square without account of increase of its absorption ability and by location of semi-conductors with same quantity, it will provide decrease of catching radiation in boarder of 3,5\%. By this not significant value the resulting surface's roughness will increase absorption of radiation with overtaking this parameter in compare with existing analogues.

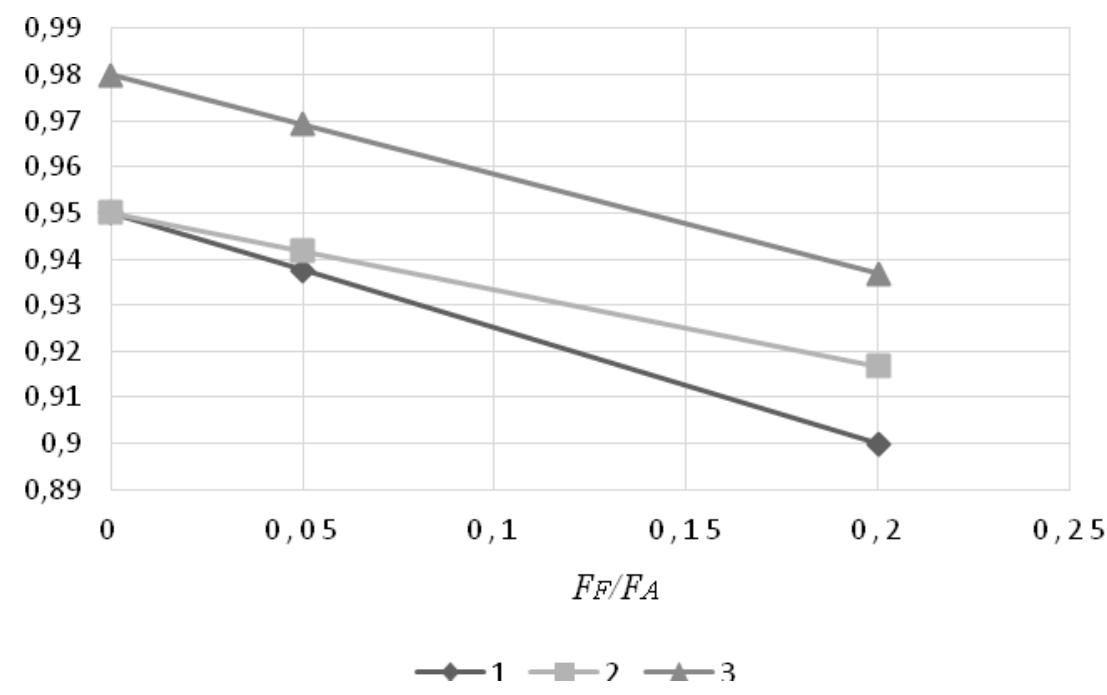

Fig. 4. Dependence absorption coefficient $A_{0}$ from relation of squares of photo transformers $F_{F}$ and absorber's surface $F_{A}: 1$ - without laser processing and absorber; 2 - with increase of absorber's square on $30 \%$ from ultra-thin ribbing; 3 - with increase of absorber's square on $30 \%$ from ultrathin ribbing with taking into account rise of absorption coefficient.

\section{Conclusions}

Further development of solar energy will active go in direction of design of innovative multi-functional solar collectors through they will be increase share of substitution of consumption of traditional resources to cover loadings of life-support systems of buildings. Appearance of photo-elements in solar units not significantly decrease efficiency of heat processes, but provide energy and exploitation stability of solar heat supply systems.

In the our designed flat solar collector [12] semi-conductors are fixed on polymeric tubes outer surface. This solution is for their cooling and further for preliminary warm-up of coolant, that enter to solar unit. Our offered laser processing of absorber's surface will increase its absorption coefficient, which in whole with preliminary warm-up allow to get coolant with higher features for the consumer.

\section{References}

1. V.I. Zemskov, Renewable sources of energy in agricultural industry (Saint-Petersburg, 2014) 
2. T.V. Shchukina, R.S. Shevchenko, Sanitary engineering. Heating. Conditioning 4, 5860 (2017)

3. A.Yu. Novichikhin, T.V. Shchukina, S.A. Ivanov, A.V. Polukazakov, R.S. Shevchenko, Science Herald of Voronezh state architectural-construction university, Series "High technologies. Ecology", 132-139 (2017)

4. V. Guiheneuf, O. Riou, F. Delaleux, P.O. Logerais et al., Trans. ASME. J. Sol. Energy Eng. 5(139), 041006/1-041006/6 (2017)

5. T.V. Shchukina, A.K. Tarkhanov, D.M. Chudinov, Sanitary engineering. Heating. Conditioning 1, 82-84 (2014)

6. P. Wang, K. Vafai, Trans. ASME. J. Sol. Energy Eng. 5(139), 051005/1-051005/7 (2017)

7. V.S. Gazalov, A.V. Braginetz, Innovations in agriculture 3(8), 119-123 (2014)

8. F.N. Yasser, S. Alsadi, Trans. ASME. J. Sol. Energy Eng. 6(138), 061005/1-061005/8 (2016)

9. A.V. Belousov, Yu.A. Koschlich, V.K. Stan, Innovation, information and communication technologies (INFO-2016): Collection of the 13th science-practical conference, 485-488 (2016)

10. N.D. Shishkin, R.A. Iljin, Vestnik Astrakhanskogo gosudarstvennogo tehnicheskogo universiteta 3, 52-60 (2016)

11. M. Beccali, M. Cellura, S. Longo, F. Guarino, Sol. Energy Mater. and Sol. Cells 156, 92-100 (2016)

12. T.V. Shchukina, D.M. Chudinov, N.V. Kuznetcova, Patent 2538152, F24J 2/26 (2015)

13. V.V. Buhmirov, Heat-and mass transfer (Ivanovo, 2014) 